\title{
Fracture Care Challenges in Austere and Combat Environments
}

\author{
Richard Judd Robins ${ }^{1}$
}

Published online: 27 April 2016

(C) Springer International Publishing AG 2016

\begin{abstract}
Management of fractures in austere environments creates significant challenges for the treating physician. Significant limitations in resources and personnel, limited or no local national health care systems, feasibility of arranging follow-up care, and adjusting to local medical standards of care all influence decision making and appropriate treatment options. In addition, ensuring the safety of medical providers and staff can influence ability to render care in hostile and dangerous environments. Early and appropriate use of antibiotics, maximizing wound care options, determining the appropriate type of fracture fixation methods, and contributing to life-saving interventions while optimizing limb function are the hallmarks of fracture care in austere and wartime conditions.
\end{abstract}

Keywords War surgery · Damage control orthopedics · Combat extremity fracture care

\section{Introduction}

Understanding fracture care in the austere, wartime environment is a significant challenge. The Global War on Terror (GWOT) in Iraq and Afghanistan represents the longest combat effort in American history. Musculoskeletal combat injury rates during GWOT have been 34.2 per 1000

This article is part of the Topical Collection on The Military Perspective

Richard Judd Robins

RobinsRJ@Hotmail.com

1 Uniformed Services University of the Health Sciences, United States Air Force Academy, 4102 Pinion Drive, USAF Academy, CO 80840, USA soldier combat-years of exposure, with $51.9-54 \%$ of all combat injuries occurring in the upper and lower extremities. $74.4-78 \%$ of injuries result from blast injury $[1,2]$. As a result of providing combat casualty care over a 14 -year period, much data has been obtained that have driven changes in treatment protocols with the goal of improving both survival and function in combat casualties. The Joint Theater Trauma System (JTTS) and the Department of Defense (DoD) trauma registry have been instrumental in providing data to drive these changes.

The hallmarks of extremity fracture care in combat environments can be defined in four broad categories: (1) prophylactic antibiotic management, (2) soft tissue/wound care management, (3) fracture stabilization, and (4) balancing acute life-saving interventions with optimizing long-term patient functional status.

\section{Antibiotic Management}

Overall infection rates in combat casualties from GWOT have been $5.5 \%$, with $27 \%$ of infections occurring as skin and wound infections [3]. Traditional guidelines for antibiotic management of open fractures in the combat environment have been to use $1 \mathrm{~g}$ of cefazolin or $600 \mathrm{mg}$ of clindamycin for Gustilo Anderson (G/A) grade I and II open fractures, and adding gram negative coverage for grade III fractures. Penicillin is added for grossly-contaminated wounds [4]. However, several changes have occurred to this protocol as a result of surveillance data of open fracture care from GWOT. The 2012 JTTS clinical practice guideline increased the dose of cefazolin to $2 \mathrm{~g}$ for all open fracture types and discouraged adding both gram negative coverage and penicillin to prevent clostridial infection [5]. 
This is based upon strong recommendations with moderate-quality evidence as presented in the 2011 guidelines for the prevention of infections associated with combat-related injuries endorsed by the Infectious Diseases Society of America and the Surgical Infection Society $[6,7]$. Murray and colleagues showed that late infections in combat casualties tended to have a higher incidence of antibiotic-resistant gram negative organisms [8]. The authors' interpretation, as supported by results from other conflicts, identify a trend in the use of broad-spectrum coverage with use of gram-negative and anaerobic organism coverage, and the subsequent development of more severe infections resulting from resistant gram-negative organisms. Further work by Burns et al. found that performing surveillance cultures, while positive $64 \%$ of the time with $93 \%$ of these cultures growing gram negative species, did not correlate in cases that eventually developed wound infections, as the majority of these infections were caused by gram-positive organisms, believed to be acquired from the health care setting [9]. As a result, current guidelines are to only use $2 \mathrm{~g}$ of cefazolin or $600 \mathrm{mg}$ of clindamycin in penicillin-sensitive individuals for all fracture patterns, and for only $24 \mathrm{~h}$ after final wound closure.

Timing of antibiotic administration continues to be a focus of policy. Previous work by Patzakis and colleagues established the trend of attempting to administer antibiotics within $3 \mathrm{~h}$ of injury to reduce the incidence of wound infection [10]. Recent data from a civilian trauma population found antibiotic administration given less than 66 min after injury correlates with a lower rate of deep infection at 90 days [11 ••]. US military protocol calls for the administration of oral moxifloxacin $400 \mathrm{mg}$ or $1 \mathrm{~g}$ of IM/IV ertapenem by field medics at the point of injury, especially if there is a tactical requirement to delay transfer urgently to a surgical facility [7]. This policy is an attempt to recognize that the austere environment can often create obstacles to optimizing care under hostile conditions affected by enemy activity or logistical obstacles in timely transport.

Finally, invasive fungal infection has been found to disproportionately affect patients severely injured in combat and austere environments. While surveillance fungal cultures have not proven to be effective, a high index of suspicion should be maintained in patients with recurrent worsening necrosis noted on serial debridement procedures [12]. Blast injury while on dismounted patrol, above-knee amputation, extensive genito-urinary or rectal injury, and massive ( $>25$ units pRBCs) transfusion have been identified as risk factors for developing an invasive fungal infection [13]. Treatment involves early use of systemic and topical anti-fungal solutions in addition to antibiotic therapy to treat the associated fungal infection.

\section{Wound Management}

\section{Debridement}

Acute management of wounds associated with open fractures in the austere environment generally follows the mantra of "treat closed fractures closed, and open fractures open." General consensus and experience have demonstrated that the most important factor in reducing infection risk in open fractures is urgent and timely surgical debridement and irrigation of the wound bed, particularly in contaminated wound beds as is often the case in open fractures that occur in austere combat environments [14•]. While a recent systematic review failed to demonstrate advantages of performing early debridement and irrigation within $6 \mathrm{~h}$ of injury, Evans and colleagues published their results on the effects of the wound environment on the development of osteomyelitis $[15,16]$. They demonstrated failure to remove both necrotic soft tissue and bone which lead to reduction in bacterial load, are the most important factors in reducing deep space infection [16]. Generally speaking, the austere environment is the greatest limiting factor to urgent debridement and irrigation of wounds. US military doctrine and deployment of resources are designed to ideally provide far-forward surgical intervention within $1 \mathrm{~h}$ of injury for life-saving intervention and limit contamination of war wounds [17]. Evidence from US involvement in Somalia demonstrated 14 of 16 patients that underwent debridement of their wounds greater than $6 \mathrm{~h}$ from injury developed infection [18].

Bowyer re-iterated the principles for acutely treating war wounds associated with open fractures: (1) excision of the skin margin, (2) generous extension of the wound with (3) exploration through all layers, and (4) excision of damaged muscle [19]. Evaluation of muscle tissue is assessed by examining color, consistency, contractility, and capacity to bleed. Traditional teaching has been to remove muscle tissue that fails to meet these criteria. Because many open fractures result from high energy trauma to the bone and soft tissues, this can lead muscle tissue to be traumatized and fail to contract on initial evaluation. This tissue can be re-evaluated in 24 72 hours on repeat wound exploration, debridement and irrigation. Several studies have documented the long-term disability resulting from "volumetric muscle loss (VML)," which is defined as the "traumatic or surgical loss of skeletal muscle with resultant functional impairment" [20-22]. Current treatment for VML is limited to physical therapy and orthotics, with significant and sometimes severe long-term disability $[21,23]$. Therefore, good judgement is advised in assessing the viability of tissue during "aggressive" debridement of war wounds, and efforts should be made to preserve as much potentially viable muscle tissue as possible. 
The surgical debridement of open fractures typically occurs in a serial fashion. Most open fractures that occur in austere environments mandate at least a second exploration to inspect the wound bed and remove any tissue that has subsequently become non-viable or necrotic. The benefits of early definitive coverage of wounds within $72 \mathrm{~h}$ of injury have been established by Godina and colleagues. These findings were supported by a recent systematic review of early vs delayed wound closure supporting early flap coverage to lower infection rates and complications [24]. However, the applicability of this approach to war wounds is limited due to the high-level of energy and contamination associated with these wounds, and need for evacuation from the austere environment to improve treatment conditions for wounded military personnel $[25,26]$. Tintle and colleagues have developed an algorithm to help determine definitive closure and soft tissue coverage in GWOT injury patients occurring from 7 days to 3 months from injury, resulting in a limb salvage rate of $94 \%$ [27]. Large et al. reported on the benefits of at least two debridement and irrigations of open fractures prior to definitive internal fixation of local nationals treated at a combat support hospital resulting in a $3 \%$ infection rate with 4 month follow-up [28•].

After initial wound debridement and irrigation, the question remains on how to manage the open wound. Infection control clinical practice guidelines recommend placing a sterile dressing in and on the open wound [6]. The advent and implementation of negative pressure wound therapy (NPWT) dressings set at $125 \mathrm{~mm} \mathrm{Hg}$ continuous pressure are now commonly employed at facilities with enough resources and a logistical chain to support this modality. Multiple studies have demonstrated the efficacy and safety of using NPWT in warwounded patients throughout the evacuation process [29-33]. While formal NPWT is an effective treatment in promoting angiogenesis, preventing skin contraction, and helping to maintain a clean surgical wound, this option is not readily available or feasible in the most austere environments, and makeshift negative pressure therapy dressings are currently discouraged in the US military JTTS clinical practice guidelines [5]. "Temporary" closure of the wound may be required when the wound bed contains exposed cartilage/joint, exposed neurovascular structures, a vascular repair site, or exposed tendon tissue [34]. In addition, a patient in shock with resultant coagulopathy may ooze through packed dressings and temporary closure of part or all of the wound for hemostatic purposes may be necessary. In these situations, it should be recognized that the "biological" bandage applied is temporary, and the wound will be re-opened within 24 to $48 \mathrm{~h}$ and explored prior to definitive closure of the wound. It is advisable in these situations to leave the wound "open" with either packing or a drain allowing for some degree of efflux from the wound bed.

Additional adjuncts to managing contaminated wound beds have also been found to be helpful. Stinner and colleagues investigated the effects of using silver-impregnated dressings in NPWT and found they assist in reducing gram positive bacterial loads in wound beds [35]. The advantages of using antibiotic impregnated polymethylmethacrylate (PMMA) beads in contaminated wounds have been wellestablished [36, 37]. Stinner et al. also studied the effects of using NPWT and antibiotic PMMA beads, and found use of PMMA beads alone better reduced bacterial load than did NPWT and PMMA used together [38 $]$.

Fracture fragments that remain connected to soft tissue should be retained. However, devitalized bone fragments with no remaining soft tissue bridge should be removed to reduce rates of infection [16, 39]. The exception to this is cases in which the bone fragment contains a hyaline cartilage surface, and loss of the articular surface will be more detrimental to long term function than risk of infection in retaining the devitalized fragment.

\section{Irrigation}

Much attention has been given to the aspect of irrigation of open fracture and war wounds. Current recommendations are for at least 3 liters of normal saline in G/A grade I open fractures, at least 6 liters for grade II, and at least 9 liters of saline in grade III injuries [5, 6, 40]. In regards to additives, Anglen conducted a randomized control trial that demonstrated safer efficacy in using castile soap over Bacitracin in irrigation; these findings were supported by Bhandari et al. in that castile soap was least toxic to osteocytes when compared to chlorhexidine and povidine [41, 42]. Work by Owens and colleagues supports the use of castile soap over other additives, but found normal saline without additives performed best at preventing rebound bacterial load at 48 hours [43]. In addition, evaluation of high pressure lavage vs low pressure/gravity/bulb irrigation has been explored. Hassinger and colleagues found high-pressure pulsatile lavage propagated bacteria into soft tissue, while Owens et al. noted higher rebound in bacterial load with pulse lavage compared to bulb syringe in infected wound beds $[43,44]$. Recent work in a 41-center randomized controlled trial provides definitive evidence that low-pressure/ bulb/gravity lavage using normal saline without additives provides the best results in reducing bacterial load when irrigating contaminated wounds $[45 \bullet \cdot, 46]$. For treatment in austere settings, these findings confirm that supplying normal saline without pulsatile lavage devices or additives provides the best level of care for contaminated open fracture wounds. 

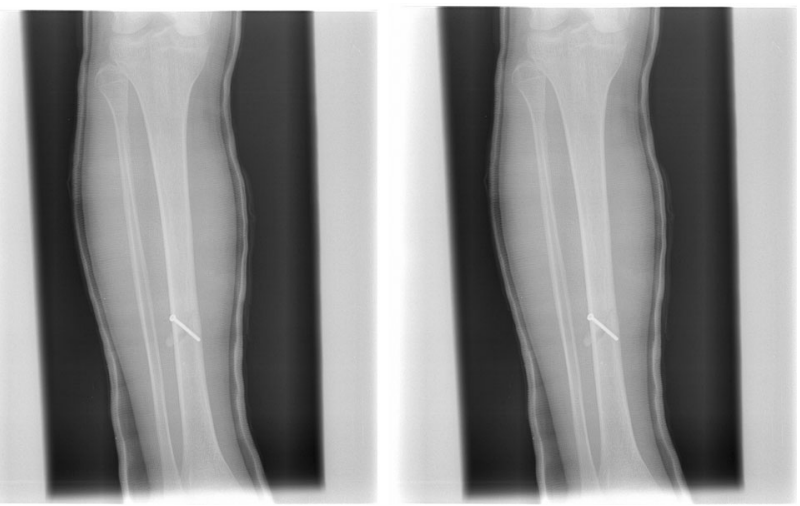

Fig 1 Example of a local national with a Gustilo-Anderson grade 1 open unstable midshaft tibial fracture treated with debridement, irrigation, limited internal fixation with a compression screw, and long-leg casting with follow-on transfer to the local military health care system for definitive management

\section{Fracture Stabilization}

Due to limitations in austere and hostile environments, ability to establish timely follow-up, and higher "demand" versus "supply" of resources available for treatment, the principle of "less is more" guides fracture stabilization. Optimal treatment options are heavily influenced by these factors versus simply selecting the best biomechanical methods of fixation for fracture treatment. Camuso outlined the benefits of stabilizing extremity fractures in the austere setting: it prevents further injury to traumatized soft tissues, reduces the risk of subsequent infection, minimizes fracture hemorrhage, blunts inflammatory mediators in poly-trauma patients, improves pain control, and facilitates patient movement/evacuation [47].

Splinting remains the treatment of choice for distal extremity injuries, and in most upper extremity fracture patterns, especially for closed fractures. For most longbone and open fractures, external fixation has become the treatment of choice for stabilization, as well as in cases of vascular injury with an unstable fracture pattern, in a poly-trauma patient, in segmental bone loss, open fractures, and in peri-articular fractures [47]. Application of external fixators in the austere environment has been found to be reliable and safe without major complications [48].

Subtle changes in patient disposition affect the type of external fixation construct applied. For western countries involved in austere environments in which third world health care systems are available, the external fixation constructs applied may hold different requirements than those of affected service members that require temporary stabilization through the evacuation chain. Previous experience in GWOT has demonstrated that US far-forward surgical teams are called upon to provide humanitarian care to the local population $[49,50]$.
The different approaches in external fixation fracture stabilization have also been documented by French military surgeons serving in GWOT and in Africa peace-keeping missions $[51,52 \bullet]$. Mathieu and colleagues discuss the benefits of converting external fixation to "definitive frame" constructs for patients, in which this method will be their definitive form of treatment, to improve bone healing and recovery of limb function [52•]. However, when follow-up or follow-on care is uncertain in a local national population, caution is advised in placing an external device instead of splinting/casting, as complications and longer hospitalizations have been noted in local-national populations [53, 54]. Past experience in Afghanistan and Iraq demonstrated that external fixators placed on local nationals without follow-up resulted in patients presenting to US military medical facilities with external fixators in place for up to 18 months with no intervening treatment following application. Nevertheless, external fixation may be the best viable options for patients with complex open fractures, associated vascular repair, or who fail splinting/casting for unstable fractures. Successful treatment of local nationals with application of definitive external fixation with follow-on transfer to the local health care system has been reported to be an acceptable approach [52•].

Limited internal fixation can be used successfully when the medical facility can replicate care delivered that is more comparable to trauma care provided in advanced health care settings. Large et al. have documented successful use of internal fixation with a low complication rate in two different role III military facilities that are able to perform care similar to a US civilian trauma center in regards to sterilization, fluoroscopic and radiological capability, and intensive care and inpatient holding capacity [28•]. Successful use of internal fixation with careful indications has been demonstrated in GWOT by other authors as well $[55,56]$. Examples

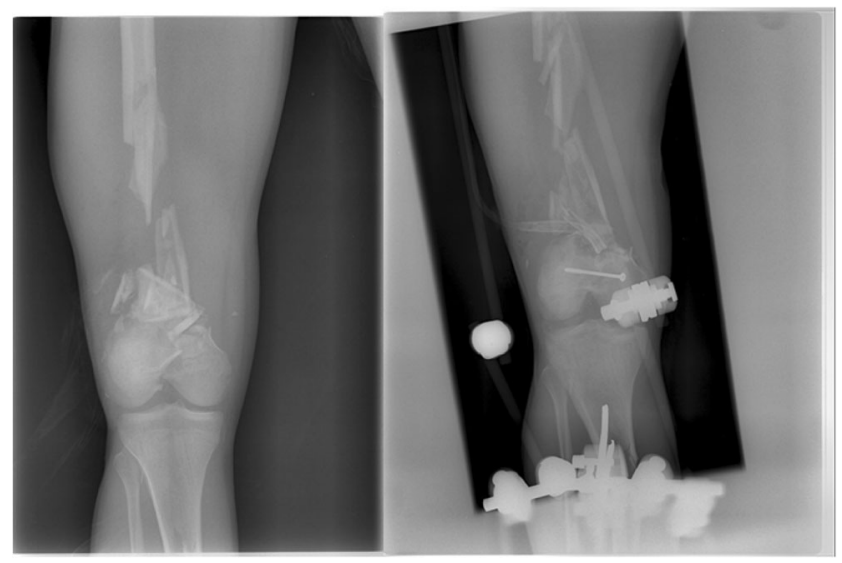

Fig. 2 Example of a comminuted intra-articular distal femoral fracture treated with limited internal fixation for reduction of the intra-articular condyle fragments and spanning external fixation prior to transfer to a local-national military hospital for definitive management 
of judicious use of internal fixation include use of compression screws of a mid-shaft G/A grade I unstable tibial fracture to maintain reduction with additional long-leg casting, or selective use of compression screws of osteochondral fragments to maintain reduction of a peri-articular distal femur fracture augmented with spanning external fixator (See Figs. 1 and 2). In addition, urgent internal fixation at a capable military facility in personnel who have suffered an intra-capsular or peritrochanteric hip fracture has been recognized as important in reducing the risk of avascular necrosis and long term disability $[57 \bullet, 58 \bullet$.

\section{Damage Control Orthopedics}

The final point to review is the prioritization of fracture care. In the setting of a poly-trauma patient presenting in-extremis, stabilization of fractures is accomplished with the goals of minimizing further soft tissue damage and the subsequent inflammatory response, control bleeding for open wounds and bone fracture sites, and contribute to controlling hemorrhage in the slightly modified "circulation $\rightarrow$ airway $\rightarrow$ breathing" Advanced Trauma Life Support primary survey. As a result, gross stabilization of limb length and alignment is more important than fracture fragment reduction, which can be accomplished at a future time once the patient has physiologically stabilized. In extreme cases, the mangled extremity may need to undergo amputation to remove the pathologic load of inflammatory mediators and source of systemic myoglobin, and to control bleeding and coagulopathy in order to preserve the patient's life.

\section{Conclusion}

Fracture care in the austere and hostile environment continues to provide significant challenges to treating surgeons. Following the principles of expeditious wound care, antibiotic management, limited initial fracture stabilization, and damage control orthopedics to contribute to preserving life and subsequent function drive both care and current and future research. Recognizing restrictions in follow-up care, limitations in available resources and dealing with highly contaminated high energy open fracture patterns define fracture care in the hostile and austere environment.

\section{Compliance with Ethical Standards}

Conflict of Interest Dr. Robins declares no conflict of interest.

Human and Animal Rights and Informed Consent This article does not contain any studies with human or animal subjects performed by any of the authors.

\section{References}

Papers of particular interest, published recently, have been highlighted as:

- Of importance

- Of major importance

1. Owens BD et al. Combat wounds in operation Iraqi freedom and operation enduring freedom. J Trauma. 2008;64(2):295-9.

2. Belmont Jr PJ et al. Combat wounds in Iraq and Afghanistan from 2005 to 2009. J Trauma Acute Care Surg. 2012;73(1):3-12.

3. Murray CK et al. Infections complicating the care of combat casualties during operations Iraqi freedom and enduring freedom. $\mathrm{J}$ Trauma. 2011;71(1 Suppl):S62-73.

4. Hauser CJ et al. Surgical Infection Society guideline: prophylactic antibiotic use in open fractures: an evidence-based guideline. Surg Infect (Larchmt). 2006;7(4):379-405.

5. Guidelines to prevent infection in combat-related injuries. J.T.T.S.C.P. Guideline, Editor. 2012, Department of Defense.

6. Hospenthal DR et al. Guidelines for the prevention of infections associated with combat-related injuries: 2011 update: endorsed by the Infectious Diseases Society of America and the Surgical Infection Society. J Trauma. 2011;71(2 Suppl 2):S210-34.

7. Hospenthal DR et al. Executive summary: guidelines for the prevention of infections associated with combat-related injuries: 2011 update: endorsed by the Infectious Diseases Society of America and the Surgical Infection Society. J Trauma. 2011;71(2 Suppl 2):S202-9.

8. Murray CK et al. Prevention of infections associated with combatrelated extremity injuries. J Trauma. 2011;71(2 Suppl 2):S235-57.

9. Burns TC et al. Microbiology and injury characteristics in severe open tibia fractures from combat. J Trauma Acute Care Surg. 2012;72(4):1062-7.

10. Patzakis MJ, Wilkins J. Factors influencing infection rate in open fracture wounds. Clin Orthop Relat Res. 1989;243:36-40.

11.• Lack WD et al. Type III open tibia fractures: immediate antibiotic prophylaxis minimizes infection. J Orthop Trauma. 2015;29(1): 16 . This paper outlines the importance of urgent administration of antibiotics as an independent risk factor in reducing risk of infection on open fractures.

12. Warkentien $\mathrm{T}$ et al. Invasive mold infections following combatrelated injuries. Clin Infect Dis. 2012;55(11):1441-9.

13. Guideline, J.T.T.S.C.P., Treatment of suspected invasive fungal infection in war wounds. D.o. Defense, Editor. 2012, Department of Defense.

14. Obremskey WT et al. Current practice in the initial management of open fractures among orthopaedic trauma surgeons. J Orthop Trauma. 2013. doi:10.1097/BOT.0000000000000033. Survey of Orthopaedic Trauma Association's orthopaedic trauma surgeons' experience in reducing open fracture infection risk, with the consensus opinion being that urgent and timely wound bed debridement is necessary to reduce risk of infection.

15. Schenker ML et al. Does timing to operative debridement affect infectious complications in open long-bone fractures? A systematic review. J Bone Joint Surg Am. 2012;94(12):1057-64.

16. Evans RP, Nelson CL, Harrison BH. The effect of wound environment on the incidence of acute osteomyelitis. Clin Orthop Relat Res. 1993;286:289-97.

17. Employment of forward surgical teams: tactics, techniques, and procedures. FM 4-02.25, D.o. Defense, Editor. 2003, Department of Defense: Washington DC.

18. Mabry RL et al. United States Army Rangers in Somalia: an analysis of combat casualties on an urban battlefield. J Trauma. 2000;49(3):515-28. discussion 528-9. 
19. Bowyer G. Debridement of extremity war wounds. J Am Acad Orthop Surg. 2006;14(10 Spec No): S52-6.

20. Cross JD et al. Battlefield orthopaedic injuries cause the majority of long-term disabilities. J Am Acad Orthop Surg. 2011;19 Suppl 1:S1-7.

21. Grogan BF, Hsu JR, C. Skeletal Trauma Research. Volumetric muscle loss. J Am Acad Orthop Surg. 2011;19 Suppl 1:S35-7.

22. Garg K et al. Volumetric muscle loss: persistent functional deficits beyond frank loss of tissue. J Orthop Res. 2015;33(1):40-6.

23. Aurora A et al. Physical rehabilitation improves muscle function following volumetric muscle loss injury. BMC Sports Sci Med Rehabil. 2014;6(1):41

24. Wood $\mathrm{T}$ et al. A systematic review of early versus delayed wound closure in patients with open fractures requiring flap coverage. $\mathrm{J}$ Trauma Acute Care Surg. 2012;72(4):1078-85.

25. Godina M. Early microsurgical reconstruction of complex trauma of the extremities. Plast Reconstr Surg. 1986;78(3):285-92.

26. Gopal S et al. Fix and flap: the radical orthopaedic and plastic treatment of severe open fractures of the tibia. J Bone Joint Surg Br. 2000;82(7):959-66.

27. Tintle SM et al. Soft tissue coverage of combat wounds. J Surg Orthop Adv. 2010;19(1):29-34.

28. Large TM, Bonds C, Howard M. Internal fixation in a combat theater hospital. Orthopedics. 2013;36(8): 610-8. A summary of experience using internal fixation methods in a combat theater hospital with low infection rates and high rates of healing with short term follow up in a local-national patient population.

29. Covey DC et al. Advances in the care of battlefield orthopaedic injuries. Instr Course Lect. 2010;59:427-35.

30. Fang $\mathrm{R}$ et al. Feasibility of negative pressure wound therapy during intercontinental aeromedical evacuation of combat casualties. J Trauma. 2010;69 Suppl 1:S140-5.

31. Powell ETT. The role of negative pressure wound therapy with reticulated open cell foam in the treatment of war wounds. J Orthop Trauma. 2008;22(10 Suppl):S138-41.

32. Pollak AN et al. Use of negative pressure wound therapy during aeromedical evacuation of patients with combat-related blast injuries. J Surg Orthop Adv. 2010;19(1):44-8.

33. Rispoli DM et al. Description of a technique for vacuum-assisted deep drains in the management of cavitary defects and deep infections in devastating military and civilian trauma. J Trauma. 2010;68(5):1247-52.

34. Sanders $\mathrm{R}$ et al. The management of fractures with soft-tissue disruptions. J Bone Joint Surg Am. 1993;75(5):778-89.

35. Stinner DJ et al. Silver dressings augment the ability of negative pressure wound therapy to reduce bacteria in a contaminated open fracture model. J Trauma. 2011;71(1 Suppl):S147-50.

36. Wahlig $\mathrm{H}$ et al. The release of gentamicin from polymethylmethacrylate beads. An experimental and pharmacokinetic study. J Bone Joint Surg Br. 1978;60-B(2):270-5.

37. Eckman Jr JB et al. Wound and serum levels of tobramycin with the prophylactic use of tobramycin-impregnated polymethylmethacrylate beads in compound fractures. Clin Orthop Relat Res. 1988;237:213-5.

38. Stinner DJ, Hsu JR, Wenke JC. Negative pressure wound therapy reduces the effectiveness of traditional local antibiotic depot in a large complex musculoskeletal wound animal model. J Orthop Trauma. 2012;26(9): 512-8. Laboratory study that demonstrates use of local antibiotic beads has higher concentrations and better effects reducing bacterial contamination of a wound bed than when combined with a negative pressure dressing.

39. Edwards CC. Staged reconstruction of complex open tibial fractures using Hoffmann external fixation. Clinical decisions and dilemmas. Clin Orthop Relat Res. 1983;178:130-61.
40. Anglen JO. Wound irrigation in musculoskeletal injury. J Am Acad Orthop Surg. 2001;9(4):219-26.

41. Anglen JO. Comparison of soap and antibiotic solutions for irrigation of lower-limb open fracture wounds. A prospective, randomized study. J Bone Joint Surg Am. 2005;87(7):1415-22.

42. Bhandari M, Adili A, Schemitsch EH. The efficacy of lowpressure lavage with different irrigating solutions to remove adherent bacteria from bone. J Bone Joint Surg Am. 2001;83-A(3):412-9.

43. Owens BD, White DW, Wenke JC. Comparison of irrigation solutions and devices in a contaminated musculoskeletal wound survival model. J Bone Joint Surg Am. 2009;91(1):92-8.

44. Hassinger SM, Harding G, Wongworawat MD. High-pressure pulsatile lavage propagates bacteria into soft tissue. Clin Orthop Relat Res. 2005;439:27-31.

$45 . \bullet$ Investigators F. A trial of wound irrigation in the initial management of open fracture wounds. N Engl J Med. 2015. Multi-center, level I randomized control trial which demonstrated the most effective wound irrigation is normal saline with no additives; additives increased wound complication and had higher infection rates.

46. Dirschl DR. Surgical irrigation of open fractures - a change in practice? N Engl J Med. 2015;373(27):2680-1. doi:10.1056/ NEJMe1512287

47. Camuso MR. Far-forward fracture stabilization: external fixation versus splinting. J Am Acad Orthop Surg. 2006;14(10 Spec No): S118-23.

48. Possley DR et al. Temporary external fixation is safe in a combat environment. J Trauma. 2010;69 Suppl 1:S135-9.

49. Robins RJ et al. Implications of humanitarian orthopaedic surgery in a combat zone: operation enduring freedom and Iraqi freedom experience. J Surg Orthop Adv. 2014;23(3):129-35.

50. Beekley AC, Watts DM. Combat trauma experience with the United States army 102nd forward surgical team in Afghanistan. Am J Surg. 2004;187(5):652-4.

51. Mathieu L et al. Damage control orthopaedics in the context of battlefield injuries: the use of temporary external fixation on combat trauma soldiers. Orthop Traumatol Surg Res. 2011;97(8):852-9.

52. Mathieu L et al. Temporary and definitive external fixation of war injuries: use of a French dedicated fixator. Int Orthop. 2014;38(8):p. 1569-76. French war surgeons experience with use of external fixation and principles of converting temporizing fixation into hybrid external fixation for definitive treatment.

53. Reis ND et al. A philosophy of limb salvage in war: use of the fixateur externe. Mil Med. 1991;156(10):505-20.

54. Rowley DI. The management of war wounds involving bone. J Bone Joint Surg Br. 1996;78(5):706-9.

55. Keeney JA et al. Closed intramedullary nailing of femoral shaft fractures in an echelon III facility. Mil Med. 2009;174(2):124-8.

56. Stinner DJ et al. Outcomes of internal fixation in a combat environment. J Surg Orthop Adv. 2010;19(1):49-53.

57. Purcell RL et al. Outcomes of war related femoral neck fractures. Injury. 2015;46(12): 2399-403. Case series of war-wounded patients that went on to have a high rate of femoral head necrosis following a traumatic femoral neck fracture.

58. Mack AW et al. Treatment of open proximal femoral fractures sustained in combat. J Bone Joint Surg Am. 2013;95(3):e13(1-8). Definitive internal fixation of open femoral neck fractures demonstrated high healing rates, low infection and femoral head necrosis rates. 